Chapman University

Chapman University Digital Commons

$9-17-2012$

\title{
Why Do Women Have More Children Than They Want? \\ Understanding Differences in Women's Ideal and Actual Family Size in a Natural Fertility Population
}

\author{
Lisa McAllister \\ University of California, Santa Barbara \\ Michael Gurven \\ University of California, Santa Barbara \\ Hillard Kaplan \\ Chapman University, hkaplan@chapman.edu \\ Jonathan Stieglitz \\ University of New Mexico
}

Follow this and additional works at: https://digitalcommons.chapman.edu/esi_pubs

Part of the Biological and Physical Anthropology Commons, Economic Theory Commons, Ethnic Studies Commons, Latin American Studies Commons, Other Anthropology Commons, Other Economics Commons, and the Social and Cultural Anthropology Commons

\section{Recommended Citation}

McAllister, L., Gurven, M., Kaplan, H., \& Stieglitz, J. (2012). Why do women have more children than they want? Understanding differences in women's ideal and actual family size in a natural fertility population. American Journal of Human Biology, 24(6), 786-799. https://doi.org/10.1002/ajhb.22316

This Article is brought to you for free and open access by the Economic Science Institute at Chapman University Digital Commons. It has been accepted for inclusion in ESI Publications by an authorized administrator of Chapman University Digital Commons. For more information, please contact laughtin@chapman.edu. 


\title{
Why Do Women Have More Children Than They Want? Understanding Differences in Women's Ideal and Actual Family Size in a Natural Fertility Population
}

\author{
Lisa McAllister ${ }^{1,{ }^{*}}$, Michael Gurven ${ }^{1}$, Hillard Kaplan ${ }^{2}$, and Jonathan Stieglitz ${ }^{2}$ \\ ${ }^{1}$ Department of Anthropology, Integrative Anthropological Sciences Program, University of \\ California-Santa Barbara, Santa Barbara, California 93106 \\ ${ }^{2}$ Department of Anthropology, University of New Mexico, Albuquerque, New Mexico 87131
}

\section{Abstract}

Objectives-We develop and test a conceptual model of factors influencing women's ideal family size (IFS) in a natural fertility population, the Tsimane of Bolivia. The model posits affects of socioecology, reproductive history, maternal condition, and men's IFS. We test three hypotheses for why women may exceed their IFS despite experiencing socioeconomic development: $\left(H_{1}\right)$ limited autonomy; $\left(H_{2}\right)$ improved maternal condition; and $\left(H_{3}\right)$ low returns on investments in embodied capital.

\begin{abstract}
Methods-Women's reproductive histories and prospective fertility data were collected from 2002 to 2008 ( $n=305$ women). Semistructured interviews were conducted with Tsimane women to study the perceived value of parental investment $(n=76)$. Multiple regression, $t$-tests, and analysis of variance (ANOVA) are used to test model predictions.
\end{abstract}

Results-Women's IFS is predicted by their socioecology, reproductive history, maternal condition, and husband's IFS. Hypotheses 2 and 3 are supported. Couples residing near town have smaller IFS (women $=3.75 \pm 1.64$; men $=3.87 \pm 2.64$ ) and less variance in IFS. However, the degree fertility exceeds IFS is inversely correlated with distance to town (Partial $r=-0.189, d f=$ $156, P=0.018)$. Women living near town have greater maternal condition but $64 \%$ value traditional skills over formal schooling and $88 \%$ believe living in town is unfeasible.

Conclusions-While reduced IFS is evident with socioeconomic development, fertility decline may not immediately follow. When perceived benefits of investment in novel forms of embodied capital are low, and somatic wealth and large kin networks persist as important components of fitness, fertility may remain high and increase if maternal condition improves.

\section{INTRODUCTION}

Among many Latin American indigenous populations, market integration and socioeconomic development are associated with increases in fertility despite declines in ideal family size (IFS) (Bremner et al., 2009; Casterline and Mendoza, 2009; Hern, 1994; Kennedy and Perez, 2000; McSweeney and Arp, 2005; Perz et al., 2008; Terborgh et al., 1995; Williams, 2011). High fertility, despite smaller IFS, may impair maternal or child health and survival and can reduce women's socioeconomic status and autonomy (Casterline and Mendoza, 2009; Gipson et al., 2008; Williams, 2011). The rapid population growth

*Correspondence to: Lisa McAllister, Integrative Anthropological Sciences Program, Department of Anthropology, University of California-Santa Barbara, Santa Barbara, CA 93106. lisamcallister@umail.ucsb.edu. 
associated with increasing fertility-e.g., 3-5\% in many Southern Amerindian populations with population doubling times of 14-23 years (Kennedy and Perz, 2000; Perz et al., 2008) -may accelerate environmental degradation of indigenous lands (Speidel et al., 2007; Williams, 2011). This is problematic as indigenous peoples face sociopolitical discrimination, and limited land rights and prospects for upward mobility (Hall and Patrinos, 2006, McNamee, 2009; Psacharopoulos and Patrinos, 1994; Speidel et al., 2007). Increases in fertility during the first stage of demographic transition are not rare (Dyson and Murphy, 1985; Gibson and Mace, 2002; Hirschman, 1994). However, the mechanisms underlying these fertility increases have not been extensively explored. Furthermore, fertility patterns observed among subsistence-level populations-populations that have only recently been exposed to Western norms, schooling, wage labor opportunities, access to contraception or healthcare-may deviate markedly from fertility patterns observed during the demographic transition of national populations in developed and developing countries, where socioeconomic development led to marked fertility declines (Borgerhoff Mulder, 1998; Kaplan, 1996; Preston et al., 2000; Vining, 1986; Wilson and Airey, 1999).

In this article, we examine the impact of socioeconomic development on women's IFS and fertility among Tsimane forager-farmers of Bolivia. The Tsimane are a natural fertility population currently undergoing market integration. However, Tsimane villages vary in their degree of socioeconomic development. The novelty of our approach is to present a conceptual framework linking fertility goals and perceptions with behavior during the initial stages of the demographic transition to small family size. We expand upon standard treatments of the demographic transition among rural indigenous populations by use of individual-level data in ethnographic context. First, we develop a conceptual model of factors influencing women's IFS. The model posits direct and indirect affects of socioecology, women's reproductive history, maternal condition, and husband's IFS. We then test three hypotheses for why women may exceed their IFS despite experiencing early stages of demographic transition: $\left(H_{1}\right)$ low female reproductive autonomy; $\left(H_{2}\right)$ improved maternal condition; and $\left(H_{3}\right)$ low returns on embodied capital investments for women and their children.

\section{Explaining ideal family size}

Women's IFS is influenced by numerous inter-related factors. Here, we examine four factors and how socioeconomic change may interact with them to affect women's IFS: (1) socioecology, (2) reproductive history, (3) maternal condition, and (4) husband's IFS. We believe these factors affect women's IFS by impacting the perceived costs and benefits of parental investment. Figure 1 depicts the relationships between these factors, IFS and fertility.

1. Socioecology-Socioecology refers to features of the physical habitat, access to food, extractive technology, and degree of market integration. Greater involvement in a competitive, skills-intensive, wage-based economy increases the importance of schooling for parents and their offspring (Kaplan, 1996; Shenk, 2009). Greater schooling and employment opportunities for women may increase women's independence and reproductive autonomy, while providing alternate "lifestyle options" beyond mothering (Borgerhoff Mulder, 2000, 2009; Cain, 1984; Caldwell, 1982; Jejeebhoy, 1995; Newson et al., 2005). These changes may encourage women to have smaller IFS, and enable them to break from cultural norms that either favor investment only in "somatic" wealth, or that measure women on the basis of their homemaker and mothering abilities.

Market integration is also associated with the breakdown of kin networks (Rosenzweig, 1988; Shenk, 2009). In many traditional societies, resource sharing within kin networks is a 
form of insurance against individual fluctuations in resource access (Fafchamps, 1992; Hoff and Sen, 2006). Increased reliance on private savings and the market instead of reciprocal sharing networks may lead to less externalizing of the costs of children, thereby encouraging smaller IFS. Kin networks are also pathways of influence and information dissemination (Hoff and Sen, 2006; Shenk, 2009). As kin influence declines, women's reproductive autonomy may increase, enabling women to state lower IFS (Newson et al., 2005, 2007).

2. Reproductive history-A woman's reproductive history influences her current IFS (Belsky et al., 1991; Miller and Pasta, 1995). In natural fertility populations, women who start reproducing earlier will have longer reproductive life spans (all else equal), higher fertility, and may state larger IFS. A woman's parity affects her IFS through postrationalization bias (Bongaarts, 1990; Bushan and Hill, 1995; Kent and Larson, 1982): women may not state IFSs lower than their current parity. Offspring sex ratio and the sex of the oldest child may affect the energetic cost of reproduction and maternal workload through access to alloparents (Hrdy, 2005; Kramer, 2005). Women with more alloparents experience reduced costs of reproduction and may thus be more willing to have large families and state correspondingly larger IFS. The number of prior marriages may have mixed effects on IFS: (1) women who change partners may have greater reproductive autonomy and thus state smaller IFS (Borgerhoff Mulder, 2009); (2) women with larger IFS may be more likely to remarry so that they can achieve their IFS; or (3) divorced women may state higher IFS as leverage to attract a new husband on the mating market.

3. Maternal condition-Agriculture and socioeconomic development are usually associated with relatively predictable access to calorically dense foods, healthcare, and public sanitation. These affect maternal morbidity, fat stores, ovarian hormone levels, and maternal energetics (Ellison, 1990; King, 2003; Nohr et al., 2009; Osteria, 1982; Voland, 1998; Wood, 1994). All else equal women with larger energy budgets have a greater capacity to support gestation and lactation while still meeting their own somatic needs (Jasienska, 2009; Valeggia and Ellison, 2003). Women in better condition may consequently be more willing to support larger families, proxied by higher IFS.

4. Husband's IFS-In natural fertility populations men generally experience lower costs of investment per child compared to women, resulting in larger IFSs for men than women (Bongaarts, 2001; Borgerhoff Mulder, 2009; Dodoo et al., 1997; Mason and Taj, 1987; Terborgh et al., 1995). Moreover, completed family size is partially determined by coital frequency, over which women may have limited control (Borgerhoff Mulder, 2009). Husbands' larger IFS may lead to higher fertility than what their wives desire, and/or may encourage wives to adjust their IFS to accommodate their husbands' needs (Kulczycki, 2008; Mason and Taj, 1987; Smuts, 1992; Voas, 2003). Education and reliance on market goods may encourage both sexes to reduce IFS, thereby reducing the divergence between husbands' and wives' IFS (Cain, 1984; Mason and Taj, 1987) and enabling women to freely state smaller IFS (Cleland and Van Ginneken, 1988; Hobcraft, 1993; Jejeebhoy, 1995; Newson et al., 2007; Riley, 1997).

\section{Hypotheses regarding the discrepancy between ideal family size and fertility}

Discrepancies between IFS and fertility have raised questions about the validity of IFS as a construct (Bongaarts, 1990). We propose that IFS is a viable representation of women's intended fertility and that the discrepancy with fertility requires explanation. Stated intentions for having additional children or for having no additional children have been shown to be reliable predictors of subsequent fertility, and important mediators in predicting several fertility-related behaviors (Bushan and Hill, 1995; Hagewen and Morgan, 2005; Rindfuss et al., 1988; Schoen et al., 1997, 1999; Thomson, 1997; Westoff, 1988; Westoff 
and Ryder, 1977). These relationships hold even after controlling for the replacement of deceased children or cultural norms of gender inequality (Bongaarts, 2001, 2002).

We investigate the empirical validity of three hypotheses to explain the discrepancy between IFS and fertility in rural indigenous populations undergoing socioeconomic transition. In the national populations of both developed and developing countries, socioeconomic development and cultural changes associated with modernization have encouraged smaller IFS (McSweeney and Arps, 2005; Terborgh et al., 1995; Westoff and Moreno, 1996; Williams, 2011). Among the Tsimane, we expect proximity to town (a proxy of socioeconomic development) to be negatively correlated with IFS in both men and women.

(H1) Female reproductive autonomy hypothesis-Women may exceed their IFS to accommodate the high fertility expectations of a spouse or kin, particularly if female reproductive autonomy is low (Borgerhoff Mulder, 2009; Dodoo et al., 1997; Jejeebhoy, 1995; Voas, 2003). Socioeconomic development may improve women's reproductive autonomy, through reducing influence of kin and increasing the economic independence of women, enabling them to achieve their desired fertility (Jejeebhoy, 1995; Newson et al., 2005). However, socioeconomic development may initially reduce women's reproductive autonomy if women's access to modern wealth, and consequently market goods and services, are controlled by their husbands (Dodoo and Seal, 1994).

Among the Tsimane, if women's reproductive autonomy is limited by their husband, we predict that fertility will show a stronger correlation with husbands' IFS than with wives' IFS (P1.1). With increasing proximity to town we predict lower discrepancies between women's IFS and parity (P1.2). An alternative prediction is that lower excess fertility (IFS - parity) may be due to lower discrepancies between husbands' and wives' IFS near town (P1.3) and not from increases in women's autonomy.

(H2) Improved maternal condition hypothesis-Greater access to healthcare, reduced morbidity, and other benefits associated with socioeconomic development may increase women's energy budgets, fecundity, and offspring survival (Cleland and Van Ginneken; 2001; Ellison, 1990; Osteria, 1982; Stearns, 1992; Valeggia and Ellison, 2003; Voland, 1998; Wood, 1994). In a natural fertility population such as the Tsimane, women in better condition should have higher parity (P2.1) and/or lower infant and child mortality than other women (P2.2).

Women residing near town are expected to have smaller IFS relative to their remotedwelling peers, but higher fertility and consequently larger discrepancies between their IFS and parity (P2.3). However, as discussed in the previous section, women in better condition may be more willing to have large families. Among more market integrated Tsimane women, those in better condition may have larger IFS (P2.4); thus, even though their fertility may be higher, we predict no corresponding increase in the discrepancy between their IFS and parity $(\mathbf{P 2} .5)$.

Predictions 2.1, 2.3, and 2.5 assume that women are not actively controlling their fertility. Use of modern contraceptives is rare among the Tsimane. Few women have used Depo Provera injections or oral contraceptive pills, and no women use contraception regularly. However, Tsimane do employ traditional methods to prevent fertilization, using cultivated plants such as bui'si mäbdyes a member of the Leguminosae family (Reyes, 2001). Its efficacy has not been assessed. Post-conception and post-partum control methods are also common, including self-inflicted physical damage to induce miscarriages and infanticide. Improvements in maternal condition increasing women's fecundity and offspring survival are a concern if women are unable to control their fertility. If Tsimane women lack effective 
methods of fertility control, women should be equally likely to have additional children, irrespective of their desired IFS (P2.6).

(H3) Low returns on embodied capital investments hypothesis-Increased fertility in rural indigenous populations may be due to incomplete market integration. Although educational and wage opportunities exist, there may still be a real or perceived lack of economic returns on investments in schooling. Additional schooling did not predict greater wage earnings in a sample of 257 Tsimane households across 13 villages, and even moderate Spanish fluency bore no association with wages (Godoy et al., 2007a).

Opportunities for wage labor are limited, male biased, and most do not require formal schooling. Rural indigenous populations also face discrimination, further limiting viable employment opportunities (Perez et al., 2008). Those with novel forms of extra-somatic wealth may achieve greater social status by remaining in their villages, and using wealth to amass traditional somatic markers of success, such as larger body size and large families. Thus, despite socioeconomic development, and declines in mortality and IFS, if somatic wealth remains the most important component of status, the motivation to deliberately control fertility will be low and fertility will remain high (Kaplan, 1996). Moreover, large families are not only an indicator of wealth and status but are also important sources of social and economic support, possibly cementing their desirability (Caldwell, 1982).

Hypothesis 3 makes similar predictions about IFS and fertility outcomes as $\mathrm{H} 2$. The discrepancy between women's IFS and parity should be greater with increased proximity to town (P2.3). However, controlling for maternal condition, we expect to see greater discrepancies between IFS and parity closer to town (P3.1). Moreover, we expect Tsimane women to express opinions suggesting that somatic wealth is the main component of perceived success (P3.2), and that investment in schooling and greater market integration is undesirable or infeasible (P3.3).

\section{METHODOLOGY}

\section{Study population}

The Tsimane are lowland South Amerindian forager-horticulturalists living in the Beni Department of Bolivia. Swidden horticulture accounts for roughly two-thirds of their diet, supplemented with fishing, hunting, and gathering. The amount of consumed fat and protein varies by proximity to rivers and primary forest where hunting is still prominent (Gurven and von Rueden, 2006). Modernization is a mosaic experience, depending on access to schools, contact with non-Tsimane, and Spanish fluency, all of which are greater closer to the nearby town of San Borja (pop. $\approx 24,000$ ). Market participation includes cash cropping of cultigens, wage labor as farmhands or loggers, and trade with merchants or missionaries. However, most wage labor opportunities are only available to men, low income, and sporadic. Residence near town is associated with greater wage-related absenteeism for men (unpublished data).

Infant mortality and total fertility rate (TFR) are high among the Tsimane [13\% infant mortality rate (IMR), TFR $=9.1$; Gurven et al., 2007]. Both IMR and TFR covary with distance to San Borja. IMR is $\sim 25 \%$ and TFR is 8.0 in remote forest villages, whereas IMR is $10 \%$ and TFR is 9.5 in villages near town (Gurven, in press). Mean \pm SD inter-birth interval (IBI) for women for whom accurate birth dates for their children are known is 30.7 \pm 10.6 months $(N=213)$ with no significant variation across villages $[F(3,209)=1.194, P=$ $0.313]$. The consistency in IBI may be due to breastfeeding practices among Tsimane women, which are relatively unaltered by market integration; breast milk has not been replaced by formula, powdered milk, or cow's milk, and most women only wean when they 
are pregnant again (mean $\pm \mathrm{SD}$ age at weaning for a subsample of 76 women was $1.74 \pm$ 0.70 years with no significant variation among villages $[F(3,72)=0.988, P=0.404]$.

\section{Data collection}

Fertility preferences and behavior of 305 Tsimane women aged 15-45 years, and 216 of their husbands, were investigated during demographic interviews by MG between 2002 and 2005. Follow-up fertility outcomes for these women were analyzed in 2008 based on censuses and interviews during medical checkups. The study sample constitutes $19 \%$ of all Tsimane women of reproductive age. Participants are from 22 villages spanning the Tsimane territory that we group into two regions: the more market integrated villages located "near town" $(N=94)$ and the more isolated villages "far from town" $(N=213)$. Villages located far from town are further divided into "Mission" $(N=63)$, remote "forest" $(N=64)$ and "riverine" $(N=86)$. The Mission village is separated from the riverine sample, despite its remote riverine location, as the Catholic Redemptorist Mission has provided schooling, religious services, medical attention, trading opportunities, and greater contact with nationals and pro-natalist beliefs for over 50 years (Gurven et al., 2007). Riverine and forest villages are considered separately because, while they are both remote regions with limited access to education and healthcare, they differ in wage labor opportunities and consumption of fish versus meat, which may affect women's health status, body composition, and physiological condition (Martin et al., 2012).

Methods used to gather reproductive histories and to ascribe ages to living and dead individuals have been previously described (Gurven et al., 2007). Demographic interviews also measured IFS, schooling (highest grade completed), literacy (coded as none/moderate/ good), and Spanish fluency (coded as none/moderate/fluent). IFS was queried as: "What number of children do you think is the best number of children for you to have so that you can live well? Think about your own experience, life and wishes. There are no correct or incorrect answers to this question."

Additional interviews conducted by LM focused on women's views on mate choice, parenting and social aspirations $(N=76 ; 59$ women from a near town village and 17 from a forest village). Five questions relevant here include: (1) "Who in your village is a good (influential) woman and why?"; (2) "Who in your village is a good (influential) man and why?"; (3) "What is important to give a child so s/he can have a good life?"; (4) "Who has the better life?" [Tsimane living far from town, close to town, those living in town, or nonTsimane living in town]; and (5) "Where would you prefer to live?" [town, close to town, or far from town]. For "What is important to give a child so s/he can have a good life?" women ranked 10 skills from most to least important: traditional skills of hunting, fishing and farming; non-traditional skills of Spanish fluency, literacy, education, access to wage labor and access to San Borja; and the uncategorized skills health and influence in the community. These questions were included to better understand how status and cultural success are viewed by Tsimane, and to assess the lifestyle options that Tsimane women believe are available to them.

Body mass index (BMI) was measured using a portable stadiometer and Tanita weigh scale, and body fat percentage (based on bioelectric impedance) using the same weigh scale. These measures were taken in the same year as demographic interviews. Women pregnant at the time of interview were not included in this study; only nonpregnant weights and body fat percentages are used. 


\section{Data analysis}

Descriptive statistics summarize IFS and TFR. Tsimane women's age and parity are strongly correlated, therefore, relationships between age, IFS and parity are assessed by partial correlations.

Table 1 summarizes key variables, measurement techniques, predicted directions, and observed effects on IFS controlling for parity, according to the schema from Figure 1. Socioecological variables include: proximity to town, used as a proxy for degree of market integration, access to healthcare and market-derived foods, and wage labor opportunities; women's schooling index, derived using principle components analysis of highest grade completed and literacy, used as a proxy for investment in embodied capital; Spanish fluency for women and their husbands, used as a proxy for interaction with non-Tsimane Bolivians; and number of surviving siblings, a proxy for availability of social support. Reproductive history variables are dated to when women stated their IFS unless stated otherwise in Table 1. Maternal condition and husbands' IFS are dated to the year women stated their IFS. Maternal energy stores is an index derived using principle components analysis of BMI and body fat percentage. Husband's schooling index is derived using principle components analysis of highest grade completed and literacy.

To test predictions outlined in Figure 1, multiple linear regression was used with IFS as the dependent variable. Women's age, age ${ }^{2}$, proximity to town, parity and a parity-by-age interaction term were controlled for. Terms associated with significance levels $<0.10$ were retained in the final model.

The three hypotheses for why fertility preferences and outcomes may differ are tested as follows:

(H1) Low female reproductive autonomy-To assess whether women or their husbands exert greater influence on fertility outcomes (P1.1), we correlate IFS discrepancy between husbands and wives with the difference in wives' parity and IFS using multiple linear regression. To assess the directionality of the relationship between proximity to town and the discrepancy between IFS and parity at interview, we use Pearson partial correlation and multiple regression (P1.2, P2.3, and P2.4). Analysis of variance (ANOVA) is used to compare the discrepancy between women's IFS and parity at interview across regions. Discrepancies between spousal IFSs by region are compared using ANOVA and paired $t$ tests (P1.3).

(H2) Improved maternal condition-To address P2.1, we assess how maternal condition varies with proximity to town and if age at menarche affects parity at interview using Pearson partial correlation. We test whether maternal energy stores predict likelihood of reproducing within three years of being interviewed using logistic regression. Whether maternal condition affects offspring mortality rate is assessed using Pearson partial correlations.

Whether women in better maternal condition are more likely to exceed their IFS (P2.3) is assessed using both logistic and linear regression. To test P2.4 and P2.5, only women in villages near town are considered and linear regression is used. We test whether women are able to control their fertility (P2.6) by considering the predictive power of women's IFS on subsequent fertility. Excluding women who were at their IFS (IFS = parity at time of interview), we divide women into two groups: "women who did not want more children" (IFS sparity at time of interview); and "women who wanted more children" (IFS > parity at time of interview). The relative risk of having additional children by 2008 , which was at 
least three years post-interview for all women, was considered across these two groups and by region using Pearson chi-square.

(H3) Low returns on embodied capital investments-To separate P3.1 from P2.3, we assess whether the discrepancy between IFS and parity varies with distance to town controlling for maternal energy stores using multiple linear regression. To assess the perceived importance of somatic versus human capital components to success (P3.2), and perceptions about the benefits of investing in human capital and the attractiveness of greater market integration (P3.3), LM's ethnographic interviews are used. For the open-ended questions "Who in your village is a good woman and why?" and "Who in your village is a good man and why?" we examined qualities of people named by respondents as worthy of respect and emulation. For other semi-structured questions, participants either ranked choices or selected one response from forced choice scenarios.

\section{RESULTS}

\section{Comparison between IFS and TFR among Tsimane and throughout Beni}

Mean \pm SD IFS for Tsimane women is $4.62 \pm 2.40$ children compared with a TFR of 9.1. This gap between IFS and TFR is much greater than that reported at the regional level of the Beni department in 2003, where both mean IFS (3.2) and TFR (4.2) are lower (Demographic and Health Surveys, 2012). On average, Tsimane women reach their IFS in their late 20s/ early 30 s, and exceed their IFS by their mid-30s (Fig. 2).

\section{Determinants of women's ideal family size}

Age and age ${ }^{2}$ account for $11.2 \%$ of the variation in women's IFS $(P<0.001)$. Controlling for age and age ${ }^{2}$, parity $(\beta=0.372, P<0.001)$ and proximity to town $(\beta=-0.254, P<$ $0.001)$ are highly significant predictors of women's IFS $[F(4,300)=20.610, P<0.001]$. Figure 3 presents women's mean IFS by region; women living in villages near San Borja have smaller IFS than women living in riverine and forest villages or near the Mission $[F(3$, $301)=6.692, P<0.001]$.

Table 2 presents the relationships between additional variables and women's IFS controlling for age, age ${ }^{2}$, parity, parity-by-age and proximity to town. These variables are considered individually due to the high number of missing values for some subjects. Of the remaining socioecological variables women's schooling index, Spanish fluency, and surviving sibship are significant predictors of women's IFS. Of the remaining reproductive history variables only number of marriages was a significant predictor of women's IFS. Of the remaining maternal condition variables only maternal energy stores was a significant predictor of women's IFS. Of the husbands' IFS variables husbands' IFS and husbands' Spanish fluency were significant predictors of women's IFS. Within a single regression model $\left[R^{2}=0.344\right.$, $F(11,145)=7.281, P<0.001]$ the variables bolded in Table 2, with the aforementioned control variables, explain $34 \%$ of the variation in women's IFS. However, women's schooling index and Spanish fluency are no longer significant predictors.

\section{The discrepancy between women's ideal family size and fertility}

(H1) Low female reproductive autonomy-There is a significant difference between husbands' and wives' IFS ( $t=-3.682, d f=216, P<0.001$ ). As presented in Figure 4, greater spousal disparity in IFS is associated with greater excess fertility for women [controlling for women's age, age ${ }^{2}$ and proximity to town: $\beta(3,212)=0.330, P<0.001$ ]. Both women's IFS (Partial $r=0.238, d f=301, P<0.001$ ) and their husbands' IFS (Partial $r$ $=0.309, d f=212, P<0.001)$ are positively correlated with parity. However, when both partners' IFS are considered simultaneously, parity is more strongly related to women's IFS 
than their husbands' IFS for those living near town and the Mission (Table 3); this pattern is reversed for forest and riverine women. P1.1 is thus not supported in villages near town and near the Mission. Furthermore, couples in which the husband wants more children while the wife does not are no more likely to have another child than couples that agree on whether to have more children or not (logistic regression controlling for proximity to town: $\beta=-0.422$ $\pm 0.370, P=0.643)$.

Controlling for age and age ${ }^{2}$, women living near town have smaller IFS (Partial $r=-0.253$, $d f=301, P<0.001$ ), but higher parity (Partial $r=0.139, d f=301, P=0.015$ ) and offspring survival (Partial $r=0.113, d f=301, P=0.049$ ). Among women aged $30-50$ years-most Tsimane women exceed their IFS in their mid-30s-there is regional variation in excess fertility $[F(3,186)=3.877, P=0.010]$. Excess fertility is greatest among women living near town $(2.50 \pm 2.50)$, followed by women living near the Mission $(1.24 \pm 2.05)$, in the forest $(1.12 \pm 3.85)$ and in riverine villages $(0.70 \pm 3.51)$. P1.2 is not supported, while P2.3 is supported.

Proximity to town is negatively correlated with IFS for both sexes. Controlling for age, age ${ }^{2}$, parity, and parity-by-age the estimated marginal mean IFS \pm SE for women living near town is $3.71 \pm 0.26$ compared with $5.11 \pm 0.17$ for women living far from town $(P<0.001)$, and $3.82 \pm 0.39$ compared to $6.26 \pm 0.25$, respectively, for their husbands $(P<0.001)$. As presented in Figure 3, couples living near town show no significant discrepancy in spousal IFS $[t(66)=-0.371, P=0.712]$, however, couples living in other regions do show discrepancies (forest $[t(45)=-2.745, P=0.009]$, Mission $[t(44)=-2.741, P=0.009$ ], riverine $[t(57)=-2.268, P=0.027])$.

Furthermore, contrary to the prediction generated by H1, husbands also exceed their IFS. There is a significant difference between husbands' IFS and their wives' parity $[F(3,210)=$ $8.640, P<0.001]$. Tukey post-hoc comparisons indicate that men living near town $(1.47 \pm$ $3.55)$ exceed their IFS more than men living in the forest $(-1.57 \pm 3.62, P<0.001)$, near the Mission $(-0.47 \pm 2.55, P=0.026)$ or in riverine villages $(-1.18 \pm 4.09, P<0.001)$. $\mathrm{P} 1.3$ is thus not supported.

(H2) Improved maternal condition-Women living in villages near town experience menarche at an average of $10.37 \pm 1.23$ months earlier $(P<0.001)$. Controlling for proximity to town, for every year menarche is delayed women marry $6.50 \pm 2.16$ months later $(P<0.001)$ and give birth $5.72 \pm 2.10$ months later $(P=0.007)$. Consequently, parityfor-age is larger in women with earlier ages at menarche (Partial $r=-0.126, d f=286, P=$ 0.033). Furthermore, women living in villages near town have larger maternal energy stores (controlling for age, age ${ }^{2}$, parity, and parity-by-age: Partial $r=0.121, d f=206, P=0.082$ ). Women with larger maternal energy stores trend towards being more likely to have another child within three years of the interview (logistic regression controlling for age, age ${ }^{2}$, parity, parity-by-age, and proximity to town and whether a woman wants more children: $\mathrm{OR}=$ $1.31, P=0.081)$. P2.1 is marginally supported.

Women's age at menarche bore no relationship to offspring survival (controlling for age, age $^{2}$ and proximity to town: Partial $\left.r=0.050, d f=192, P=0.488\right)$. However, women with larger maternal energy stores at interview had experienced fewer miscarriages and stillbirths (Partial $r=-0.143, d f=198, P=0.043$ ). P2.2 is supported.

Women with greater maternal energy stores are more likely to exceed their IFS within three years of the interview $\left(\mathrm{OR}=1.63, P=0.011\right.$, controlling for age, age ${ }^{2}$, parity, parity-by-age, and proximity to town). Maternal energy stores are also positively correlated with excess 
fertility (regression model $[F(6,205)=50.455, P<0.001]$ controlling for age, age ${ }^{2}$, parity, parity-by-age, and proximity to town: $\beta(6,205)=0.109, P=0.017)$. P2.3 is supported.

Among women living near town, women with greater maternal energy stores have smaller IFS (regression model $[F(5,50)=5.237, P=0.001]$ controlling for age, age ${ }^{2}$, parity, and parity-by-age: $\beta(5,50)=-0.283, P=0.020)$. P2.4 is therefore not supported. P2.5 is also not supported: among women living near town, women with larger maternal energy stores have greater excess fertility (regression model $[F(5,50)=25.082, P<0.001]$ controlling for age, age $^{2}$, parity, and parity-by-age: $\beta(5,50)=0.174, P=0.029$ ).

Despite the absence of effective contraceptive use, we find evidence of fertility control among the Tsimane. $51 \%$ of couples who did not want more children $(N=111)$ had another child within three years of the interview compared with $65 \%$ of couples who wanted more children $(N=105)$. Furthermore, regional comparisons of women who had exceeded their IFS with those who had not reveals that: (1) women living in riverine villages and near the Mission who want more children have a significantly greater relative risk of having another child by 2008 than women who did not want more children; while (2) near town and forest women regardless of whether they have exceeded their IFS or not experience no significant difference in risk of having another child by 2008 (Table 4).

(H3) Low returns on embodied capital investments-Controlling for the larger maternal energy stores of women living near town, age, age ${ }^{2}$, parity, and parity-by-age, women living near town still have smaller IFS [estimated marginal mean IFS \pm SE of women living in villages near town is $3.78 \pm 0.33$ compared to $5.11 \pm 0.20$ for women living far from town $(P=0.001)]$, but higher parity (Partial correlation $r=0.183, d f=207, P=$ 0.008 ) and lower offspring mortality (Partial correlation $r=-0.113, d f=301, P=0.049$ ). Consequently women living in villages near town have $1.07 \pm 0.29$ more surviving offspring than women living in villages far from town $(P<0.001)$, and exceed their IFS by $2.05 \pm$ 0.37 children more than women living in villages far from town $(P<0.001)$. P3.1 is thus supported.

Supporting P3.2, there is some evidence that women continue to prefer somatic markers of success over extra-somatic markers. When asked to identify the "influential" or "model" women in their village, respondents chose women with large families. Of 79 women residing near town over age 18 at the time of interview, only 16 were identified by respondents as "influential" or "model" women, and $46 \%$ of respondents chose one of two sisters both with family sizes one greater than the mean for their age cohort. When asked why these women were chosen $81 \%$ of women listed traditional attributes (e.g., good at gathering food, good mother, and has many children) before novel attributes (e.g., educated, speaks Spanish). Furthermore, when asked to name "good men", 76\% of respondents chose men whose wives' parity was greater than the mean parity of their wives' age cohorts. When asked why these men were chosen $67 \%$ of women listed traditional attributes (e.g., good hunter and farmer) before novel attributes (e.g., does a lot of wage labor, educated, speaks Spanish).

Prediction 3.3 is supported. When asked whether they thought Bolivian nationals or Tsimane living in various locales had a "better life," more women reported that Tsimane living in remote villages had a better life than Tsimane living near or in town, while nationals were believed to have relatively good lives regardless of where they lived $(P<$ 0.005). Bolivian nationals in town were believed to have significantly better lives than Tsimane living in town $(P=0.004)$. Consistent with their reports about the "good life," both forest and near town women said they would prefer to live far from town rather than in or near town (Fig. 5). Moreover, embodied capital, in the form of formal education, Spanish 
fluency and literacy, did not appear as salient resources to invest in children. For all women, traditional skills such as fishing, hunting, and farming were deemed most important. Two or more of these traditional skills were selected within the top three choices by $87 \%(N=76)$ of women $\left(X^{2}=27.240, d f=3, P<0.001\right)$, with $49 \%$ of women listing hunting, fishing, or farming skills as their primary selection $\left(\mathrm{X}^{2}=13.04, d f=2, P=0.001\right)$. Education, ability to speak Spanish and literacy, if chosen, were listed after traditional skills by $64 \%$ of women, appearing as primary selection for only $29 \%$ of women. Moreover, women's schooling index and Spanish fluency had no affect on women's parity-for-age (residual of age and $\mathrm{age}^{2}$ regressed on parity) when controlling for proximity to town $[F(3,301)=0.923, P=$ $0.430]$.

\section{DISCUSSION}

Tsimane women have high fertility and indications among the youngest cohort are that fertility may increase further. These patterns exist even though women state preferences for lower fertility. Most Tsimane women exceed their IFS by their mid-30s and young women living near town are predicted to exceed their IFS the most. Young women living near town have the lowest IFS $(<25$ years old $=3.03 \pm 1.69)$ but highest TFR $(9.58)$ and lowest IMR $(<10 \%)$; they are therefore predicted to exceed their IFS by up to six children. In contrast, women residing in the interior forest have larger IFS ( $<25$ years old $=4.30 \pm 2.80)$, lower TFR (8.01) and higher IMR (up to 25\%); they are predicted to exceed their IFS by only two children. The Tsimane's high fertility and associated 3\% annual population growth is unsustainable, especially closer to town where environmental degradation and competition for land and resources with Bolivian nationals is greater. Therefore, among Tsimane women, as with many South Amerindian women, determining why IFS and fertility rarely coincide is an important question.

\section{Determinants of women's ideal family size}

Tsimane women's IFS is influenced by components of their socioecology, reproductive history, maternal condition, and husbands' IFS.

1. Socioecology-Women living in villages near town prefer smaller families than women living far from town. Near town, educational opportunities and quality of schools are greater. Education encourages a desire for reduced reproduction either directly, by highlighting economic, social, and health benefits of a smaller family, or indirectly by encouraging women to delay reproduction and invest more in their own education and that of their children (Cleland and Van Ginneken, 1988; Jejeebhoy, 1995; Leonetti et al., 2007; Newson et al., 2007; Riley, 1997). This broad association is supported here, as women with more schooling have smaller IFS after controlling for town proximity. Women near town also interact more with non-Tsimane-individuals that may be considered to have good and successful lives (Fig. 5). Tsimane women may wish to emulate non-Tsimane and adopt similar preferences for lower fertility if this is perceived to facilitate success. Women living near town may also have had more exposure to NGO-sponsored workshops on reproductive health and family planning, and family planning advice from medical professionals working in town.

Women with larger surviving sibships were expected to have larger IFS due to greater access to allocare reducing the cost of childrearing. However, among our Tsimane sample, women with larger surviving sibships have smaller IFS. Women's sibship size may affect their childhood experiences of resource access and perceptions of how difficult it is to raise a large family (Belsky et al., 1991). In future research residential proximity, closeness in 
age, and relationship quality should be factored in for each sibling, as these affect women's perceived access to kin support.

2. Reproductive history-Women's parity has the strongest positive association with IFS. Women rarely state IFS lower than their current parity, consistent with postrationalization bias (Kent and Larson, 1982).

Women who have remarried have higher IFS. Although remarriage rates among Tsimane women are low (10\%, unpublished data), a remarried woman presumably includes in her IFS her children from previous marriages and expectations for more children in a new union. Although multiple marriages may often lower fertility outcomes, as among Pimbwe women of Tanzania (Borgerhoff Mulder, 2009), compared to Tsimane women, Pimbwe women are less dependent on men for resources because of strong maternal kin support and greater integration into the market economy. Alternatively, divorcees and widows of reproductive age who are pro-natalist may be more likely to remarry.

Women's age at first birth does not affect their IFS, suggesting women do not take into account the length of their potential reproductive life span when considering their IFS. Moreover, having more "helpers at the nest" (oldest child being female or a female biased offspring sex ratio) had no significant affect on IFS. These results, coupled with the finding that larger surviving sibships were associated with smaller IFS, suggests that availability of alloparents may not influence women's IFS.

3. Maternal condition-Women in better maternal condition have larger IFS. Women with higher BMI and body fat percentage are likely in better health and better able to support infant growth; their better condition may increase their willingness to have larger families.

4. Husband's IFS-Husband's IFS is significantly correlated with women's IFS, suggesting assortative mating. Assortative mating among the Tsimane has been shown for some personality traits (Godoy et al., 2008), and work effort independent of parity (Gurven et al., 2009). Alternatively, Tsimane women may have low reproductive autonomy and adjust their IFS to match their husbands' IFS. Whether Tsimane women have low reproductive autonomy is discussed below.

Women with Spanish-speaking husbands have lower IFS. Men more fluent in Spanish may be less traditional and allow their wives more autonomy. Also, men more fluent in Spanish are more likely to engage in wage labor, which is associated with paternal disinvestment (e.g., extra-marital affairs) (Stieglitz et al., 2011). Paternal disinvestment may encourage women to reduce their IFS. Factors that predict men's IFS will be analyzed in a forthcoming article.

\section{The discrepancy between women's ideal family size and fertility: evaluating the three hypotheses}

(H1) Low female reproductive autonomy-Hypothesis 1 is not supported. Parity for women living in villages near town is more strongly correlated with wives' IFS than with husbands' IFS (P1.1, see Table 3). Furthermore, couples in which the husband wants more children but the wife does not are no more likely to have another child within three years of interview than couples in accordance. However, Tsimane women are more likely to exceed their IFS as the discrepancy between their IFS and their husbands' IFS increases, suggesting low reproductive autonomy for some Tsimane women. 
Excess fertility is greatest in women living near town (P1.2 is not supported while P2.3 is supported). However, near town spousal disparity does not explain variation in extent of excess fertility above women's IFS (P1.3). Moreover, women and their husbands have smaller and more similar IFS near town. Therefore, while low female autonomy and husbands' larger IFS may explain why women living away from town exceed their IFS, they do not explain excess fertility among couples living near town.

(H2) Improved maternal condition-Hypothesis 2 is weakly supported. Women in better condition have higher parity (P2.1), are more likely to have another child within three years of the interview (P2.1) and have fewer miscarriages and stillbirths (P2.2). However, women in better condition have smaller IFS and thus exceed their IFS more than women in poorer condition (P2.3).

Women living in villages near town are in better condition than their remote-dwelling peers. However, in contrast to P2.4 and P2.5, among women living near town, those in better condition have the smallest IFS and greatest excess fertility. Education, interactions with non-Tsimane, and other factors associated with proximity to town, may outweigh the affect of maternal condition on IFS.

Although infanticide is increasingly condemned among educated Tsimane, women have numerous sanctioned pre-conception and post-conception methods of fertility control. " $A$ woman can take care of herself, she can get an injection. She can drink herbal concoctions to not have children. . . and her husband knows" (woman living near town). Women living near town have easier access to modern contraceptives as well. One might therefore expect Tsimane women living near town to have lower fertility, despite their improved condition. However, women near town show no evidence of effective fertility control (P2.6), while women living near the Mission and in riverine villages showed significant control over their fertility. The greater fertility control of women living in riverine villages and near the Mission may be due to better access to herbal methods of fertility control: "Women (in villages) near town. . . they have forgotten about the plants of the forest and their mothers do not teach them. And, near town you have to grow the plants in your house garden if you want them, the forest is too used [exploited for agriculture and logging] to find the plants easily. So, they cannot help but have many babies" (woman living in a riverine village). Despite potentially greater fertility control farther from town, women and their husbands in these regions still exceed their IFS. The historic demographic transitions in Europe began before the advent of modern contraceptives (Preston et al., 2000). So while access to modern contraceptives may assist women in reducing fertility, access per se may not be fundamental to the process. Family planning programs that focus on improving access to modern contraceptives may thus be less effective than those focusing on truly reducing IFS first, e.g., those that increase perceived benefits of investment in human capital (Bledsoe et al., 1998; Pritchett, 1994; Schultz, 1969).

(H3) Low returns on embodied capital investments-Hypothesis 3 is supported. The larger discrepancy between IFS and fertility in women living in villages near town holds even after controlling for maternal condition (P3.1). Interviews suggest that Tsimane women: (1) recognize that small families are easier to manage, but, as success and security are still defined in terms of family and social connections, the predilection to have large families persists, even amongst those living under more modern conditions (P3.2); (2) Tsimane women still believe their children need traditional skills more than education or Spanish fluency, suggesting that the desire to invest heavily in these non-traditional forms of human capital for themselves or their children may still be low (P3.3); and (3) Tsimane women believe that life in town, where nontraditional human capital and life ways are important, is not ideal, and is also unavailable, and express a preference for more traditional 
life ways (P3.3). However, Tsimane women do rate non-Tsimane as having the better life and perhaps wish to emulate those lives. This may help explain smaller stated IFS near town despite the continued belief that large families are important for success.

A few quotes from female participants living near San Borja lend additional support for H3. The value of children in terms of household economics and desirability is a salient theme: "Large family is good so children can work for the family, daughters can help make chicha and sons can hunt and fish" (16 year old woman). As is the difficulty of life in San Borja for Tsimane: "Napos [non-Tsimane] do not like Tsimane in San Borja and the work is hard. San Borja is expensive and [Tsimane] make little money. .." (adult woman). Tsimane do emphasize the value of learning Spanish, but not of formal education: "It's important that sons and daughters can speak Spanish. . . so they can sell [agricultural products] to Napos. If you cannot speak Spanish the Napos cheat you. .." (adult woman); and wage labor is acknowledged as a male domain: "Women who work [for money], they are not respected, they are not good mothers. . good Tsimane women look after children and clean the house." (adult woman).

As of yet lives outside of the Tsimane territory are not feasible options for the Tsimane, who like many other indigenous populations, face discrimination and have cultural norms and egalitarian traditions regarding resource distribution that limit the accumulation of individual wealth and private security (Hern, 1994; Jackson, 1975; Lu, 2007; McSweeney and Arps, 2005; Ribeiro, 1967; Terborgh et al., 1995). Hypergyny is uncommon and outmigration is only $7.1 \%$ of the population (Godoy et al., 2007b). Therefore, the Tsimane continue to live fairly traditional lives, and continue to measure success predominantly in terms of somatic wealth, i.e., physical size and family size. However, for Tsimane men, nontraditional and novel skills increasingly beget community leadership, although influence, prestige and reproductive success are still highly correlated with traditional skills (von Rueden, 2008). Greater access to market goods and services, and improvements in maternal condition enable women to increase their fertility, potentially increasing their status within their village. Tsimane who have pursued interests in education, wage labor, and the local market economy may soon be at a crossroads: move to town and enter at the lowest rung of an aggressive economy, or stay within their traditional territory, have many children and be considered highly successful.

This article has begun to address why natural fertility populations do not follow the standard path to low fertility in the early stages of demographic transition. Pre-transition increases in fertility have been extensively documented (e.g. Dyson and Murphy, 1985; Hirschman, 1994) but rarely explored in depth. We propose that it is the continued preference for somatic markers of success, and the lack of perceived and actual returns on investments in schooling that contribute to a desire for high fertility. A similar pattern has been documented among the Arsi Oromo of Ethiopia undergoing development initiatives but increased fertility (Gibson and Mace, 2002, 2006). This implicit desire for high fertility, coupled with higher fecundity due to improved maternal condition, may explain Tsimane high fertility and rapid population growth. Modernization may not improve Tsimane women's long-term nutritional and health status if extra energy is used to invest in more offspring. Moreover, while effective birth control options now exist, they may be inaccessible for many, and the desire to obtain them remains weak. Therefore, women may increase their social status by continuing to invest in high fertility.

The prospect for future demographic change in the Tsimane is uncertain. Tsimane children today receive more education than their parents did, and the gender inequality in educational attainment has decreased substantially. For example, Tsimane girls and boys aged 10-19 now have an average of 3.2 and 3.5 years of schooling, respectively, compared with 0.4 and 
1.3 years of schooling among women and men aged $40+$. However, the quality of Tsimane schools remains low compared to schools in San Borja and higher education is too expensive for most Tsimane to attend. Moreover, the benefits of a good education continue to be low as employment opportunities are predominantly low wage, short term, male biased, and require limited schooling.

Our model attempts to explain women's reproductive decision making by focusing not only on schooling and wealth but also on beliefs about current and future conditions, social support, and pressure from spouses. Future studies would benefit from gathering explicit data on fertility preferences and variation in spousal discrepancy in IFS, and qualitative data on perceptions and beliefs pertaining to why women in high fertility populations may exceed their IFS. There is a great need for broader studies that focus on multiple factors and for attention placed particularly on the discrepancy between fertility preferences and outcomes among high fertility indigenous populations in developing countries. Gaining a better understanding of how women internalize and integrate traditional ideas from respected peers, novel ideas about reproductive technologies, expectations of future conditions and social support, and the value placed on investments in human capital is critical to best understand how the pace of fertility will change in the near future. It is also important to investigate mechanisms for reducing fertility without use of contraceptives, as these methods may have greater efficacy with marginalized indigenous populations.

\section{Acknowledgments}

Contract grant sponsor: National Science Foundation; Contract grant numbers: BCS-0136274, BCS-0422690 and BCS-1060319; Contract grant sponsor: National Institutes of Health/National Institute on Aging; Contract grant number: 1R01AG024119-01; Contract grant sponsor: UCSB Academic Senate grant and UCSB Humanities and Social Sciences Research Grant.

The authors thank the Tsimane and the Gran Consejo Tsimane for their patience, collaboration, and hospitality. They are especially grateful to many Tsimane assistants and Bolivian nationals who helped facilitate research in Bolivia during the period of data collection 2002-2008, such as Benigna Mayer Maito, Matilde Maito Tayo, Ramon Vie Tayo, Alberto Maito Tayo, Feliciano Cayuba Claros, Maguin Gutierrez, Benito Tayo and Fredi Nate, and Jorge Añez Claros. They also thank Victoria Schlegel for her help coding the demographic data, and Christopher von Rueden, Melanie Martin, Aaron Blackwell, and Anne Pisor for their advice and support throughout the preparation of this article.

\section{LITERATURE CITED}

Belsky J, Steinberg L, Draper P. Childhood experience, interpersonal development, and reproductive strategy: an evolutionary theory of socialization. Child Dev. 1991; 62:647-670.

Bledsoe C, Banja F, Hill A. Reproductive mishaps and Western contraception: an African challenge to fertility theory. Popul Dev Rev. 1998; 24:15-57.

Bongaarts J. The measurement of wanted fertility. Popul Dev Rev. 1990; 16:487-506.

Bongaarts J. Fertility and reproductive preferences in post-transitional societies. Popul Dev Rev. 2001; 27:260-281.

Bongaarts J. The end of the fertility transition in the developed world. Popul Dev Rev. 2002; 28:419443.

Borgerhoff Mulder M. The demographic transition: are we any closer to an evolutionary explanation? Trends Ecol Evol. 1998; 13:266-270.

Borgerhoff Mulder M. Optimizing offspring: the quantity-quality tradeoff in agropastoral Kipsigis. Evol Human Behav. 2000; 21:391-410.

Borgerhoff Mulder M. Tradeoffs and sexual conflict over women's fertility preferences in Mpimbwe. Am J Hum Biol. 2009; 21:478-487.

Bremner J, Bilsborrow R, Feldacker C, Lu Holt F. Fertility beyond the Frontier: Indigenous women, fertility, and reproductive practices in the ecuadorian amazon. Popul Environ. 2009; 30:93-11. 
Bushan, I.; Hill, K. Johns Hopkins Population Center. New York: Department of Population Dynamics, Johns Hopkins University; 1995. The measurements and interpretation of desired fertility.

Cain, M. Women's status and fertility in developing countries: son preference and economic security. Washington DC: World Bank; 1984.

Caldwell, J. Theory of fertility decline. New York: Academic; 1982.

Casterline, JB.; Mendoza, JA. Unwanted fertility in Latin America: historical trends, recent patterns, paper presented at the annual meeting of the Population Association of America. Detroit, Michigan: 2009.

Cleland JG, Van Ginneken JK. Maternal education and child survival in developing countries: the search for pathways of influence. Soc Sci Med. 1988; 27:1357-1368.

Cleland JG. The effects of improved survival on fertility: a reassessment. Popul Dev Rev. 2001; 27:60-92.

Demographic and Health Surveys. 2012. Available at: http://www.measuredhs.com, Retrieved July 11, 2012.

Dodoo FN, Seal A. Explaining spousal differences in reproductive preferences: a gender inequality approach. Popul Environ. 1994; 15:379-394.

Dodoo FN, Luo Y, Panayotova E. Domale reproductive preferences really point to a need to refocus fertility policy? Popul Res Policy Rev. 1997; 16:447-455.

Dyson T, Murphy M. The onset of fertility transition. Popul Dev Rev. 1985; 11:399-440.

Ellison P. Human ovarian function and reproductive ecology: new hypotheses. Am Anthropol. 1990; 92:933-952.

Fafchamps M. Solidarity networks in pre-industrial societies: rational peasants in a moral economy. Econ Dev Cult Chang. 1991; 41:147-174.

Gibson MA, Mace R. Labor-saving technology and fertility increase in rural Africa. Curr Anthropol. 2002; 43:631-637. [PubMed: 15125420]

Gibson MA, Mace R. An energy-saving development initiative increases birth rate and childhood malnutrition in rural Ethiopia. PLoS Med. 2006; 3:476-484.

Gipson JD, Koenig MZ, Hindin M. The effects of unintended pregnancy on health outcomes: a review of the literature. Stud Fam Plann. 2008; 39:18-38. [PubMed: 18540521]

Godoy R, Reyes-García V, Seyfried C, Huanca T, Leonard WR, McDade T, Tanner S, Vadez V. Language skills and earnings: evidence from a pre-industrial economy in the Bolivian Amazon. Econ Educ Rev. 2007a; 26:349-360.

Godoy R, Reyes-García V, Huanca T, Tanner S, Seyfried C. On the Measure of income and the economic unimportance of social capital: evidence from a native Amazonian society of farmers and foragers. J Anthropol Res. 2007b; 63:239-260.

Godoy R, Eisenberg DTA, Reyes-García V, Huanca T, Leonard WR, McDade TW, Tanner S. Assortative mating and offspring wellbeing: theory and empirical findings from a native Amazonian society in Bolivia. Evol Hum Behav. 2008; 29:201-210.

Gurven M, von Rueden C. Hunting, social status and biological fitness. Soc Biol. 2006; 53:81-99. [PubMed: 21516952]

Gurven M, Kaplan H, Zelada Supa A. Mortality experience of Tsimane Southern Amerindians: regional variation and temporal trends. Am J Hum Biol. 2007; 19:376-398. [PubMed: 17421012]

Gurven M, Winking J, Kaplan H, von Rueden C, McAllister L. A Bioeconomic approach to marriage and the sexual division of labor. Hum Nat. 2009; 20:151-183.

Gurven M. Infant and fetal mortality among a high fertility and mortality population in the Bolivian Amazon. Soc Sci Med. (in press).

Hagewen J, Morgan S. Intended and ideal family size in the United States: 1970-2002. Popul Dev Rev. 2005; 31:507-527. [PubMed: 20376334]

Hall, G.; Patrinos, HA. Indigenous people, poverty and human development in latin America: 19942004. New York: Palgrave Macmillan; 2006.

Heer, DM. Determinants of fertility in developing countries. Vol. Vol. 1. New York: Academic Press; 1983. Infant and child mortality and the demand for children; p. 369-387. 
Hern, W. Health and demography of native Amazonians: historical perspective and current status. In: Roosevelt, A., editor. Amazonian Indians from Prehistory to Present. Tucson, AZ: University of Arizona Press; 1994. p. 123-150.

Hirschman C. Why fertility changes. Annu Rev Sociol. 1994; 20:203-233. [PubMed: 12318868]

Hobcraft J. Women's education, child welfare and child survival: a review of the evidence. Health Transit Rev. 1993; 3:159-175. [PubMed: 10146571]

Hoff, K.; Sen, A. The kin system as a poverty trap?. In: Bowles, S.; Durlauf, SN.; Hoff, K., editors. Poverty traps. New Jersey: Princeton University Press; 2006. p. 95-115.

Hrdy, S. Comes the child before the man: how cooperative breeding and prolonged post-weaning dependence shaped human potentials. In: Hewlett, B.; Lamb, M., editors. Hunter-gatherer childhoods. Somerset, NJ: Piscataway; 2005. p. 65-91.

Jasienska G. Reproduction and lifespan: trade-offs, overall energy budgets, intergenerational costs, and costs neglected by research. Am J Hum Biol. 2009; 21:524-532. [PubMed: 19367577]

Jejeebhoy, SJ. Women's education, autonomy, and reproductive behaviour. New York: Oxford University Press; 1995.

Kaplan H. A theory of fertility and parental investment in traditional and modern human societies. Am J Phys Anthropol. 1996; 101:91-135.

Kennedy DP, Perz SG. Who are Brazil's indigenous? Contributions of census data analysis to anthropological demography of indigenous populations. Hum Org. 2000; 59:311-324.

Kent, M.; Larson, A. Family size preferences: evidence from the World Fertility Surveys. Vol. Vol. 4. Washington DC: Population Reference Bureau; 1982.

King JC. The risk of maternal nutritional depletion and poor outcomes increases in early or closely spaced pregnancies. J Nutr. 2003; 133:1732S-1736S. [PubMed: 12730491]

Kramer KL. Children's help and the pace of reproduction: cooperative breeding in humans. Evol Anthropol. 2005; 14:224-237.

Kulczycki A. Husband-wife agreement, power relations and contraceptive use in Turkey. Int Fam Plan Perspectives. 2008; 34:127-137.

Leonetti D, Nath D, Hemam N. The behavioral ecology of family planning. Hum Nat. 2007; 18:225241.

Lu F. Integration into the market among indigenous peoples: a cross-cultural perspective from the Ecuadorian Amazon. Curr Anthropol. 2007; 48:593-602.

Martin MA, Lassek WD, Gaulin SJC, Evans RW, Woo JC, Geraghty SR, Davidson BS, Morrow AL, Kaplan HS, Gurven MD. Fatty acid composition in the mature milk of Bolivian foragerhorticulturalists: controlled comparisons with a U.S. sample. Mat Child Nutr. 2012; 8:404-418.

Mason K, Taj A. Differences between women's and men's reproductive goals in developing countries. Popul Dev Rev. 1987; 13:611-638.

McNamee CB. Wanted and unwanted fertility in Bolivia: does ethnicity matter? Int Perspect Sex Reprod Health. 2009; 35:166-175. [PubMed: 20123650]

McSweeney K, Arps S. A "demographic turnaround": the rapid growth of the indigenous populations in lowland Latin America. Lat Am Res Rev. 2005; 40:3-29.

Melgar, T. Detrás del cristal con que se mira: mujeres Tsimane, órdenes normativos e interlegalidad. Bolivia: Gran Consejo Tsimane y Centro de Investigación y Documentación para el Desarrollo del Beni; 2009.

Miller W, Pasta D. How does childbearing affect fertility motivations and desires? Soc Biol. 1995; 42:185-198. [PubMed: 8738545]

Newson L, Postmes T, Lea S, Webley P. Why are modern families small? Toward an evolutionary and cultural explanation for the demographic transition. Pers Soc Psychol Rev. 2005; 9:360-375. [PubMed: 16223357]

Newson L, Postmes T, Lea S, Webley P, Richerson P, Mcelreath R. Influences on communication about reproduction: the cultural evolution of low fertility. Evol Hum Behav. 2007; 28:199-210.

Nohr E, Vaeth M, Rasmussen S, Ramalau-Hansen C, Olsen J. Waiting time to pregnancy according to maternal birthweight and prepregnancy BMI. Hum Reprod. 2009; 24:226-232. [PubMed: 18819963] 
Osteria TS. Maternal nutrition, infant health, and subsequent fertility. Philipp. J Nutr. 1982; 35:106111. [PubMed: 12266149]

Palmore JA, Concepcion MB. Desired family size and contraceptive use: an 11-country comparison. Int Fam Plan Perspec. 1981; 7:37-40.

Perz SG, Warren J, Kennedy D. Contributions of racial-ethnic reclassification and demographic processes to indigenous population resurgence: the case of Brazil. Lat Am Res Rev. 2008; 43:733.

Preston, S.; Heuveline, P.; Guillot, M. Demography: measuring and modeling population processes. New York: Wiley-Blackwell; 2000.

Pritchett LH. Desired fertility and the impact of population policies. Popul Dev Rev. 1994; 20:1-55.

Psacharopoulos, G.; Patrinos, HA. Indigenous people and poverty in Latin America: an empirical analysis. Washington, DC: The World Bank; 1994.

Reyes, V. Ph.D. Dissertation. FL: University of Florida; 2001. Indigenous people, ethnobotanical knowledge, and market economy. A case Study of the Tsimane' Southern Amerindians in Lowland Bolivia.

Ribeiro, D. Indigenous cultures and languages of Brazil. In: Hopper, J., editor. Indians of Brazil in the Twentieth Century. Washington DC: Institute for Cross-Cultural Research; 1967. p. 77-167.

Riley NE. Gender, power, and population change. Popul Bull. 1997; 52:1-48. [PubMed: 12292663]

Rindfuss, R.; Morgan, S.; Swicegood, G. First births in America: changes in the timing of parenthood. Berkeley: University of California Press; 1988.

Rosenzweig, MR. Labor markets in low income countries. In: Hollis, C.; Srinivasan, TN., editors. Handbook of development economics. Vol. Vol. 1. Amsterdam: North Holland Press; 1988. p. 713-762.

Schoen R, Young K, Nathanson CA, Fields JM, Astone NM. Why do americans want children? Popul Dev Rev. 1997; 23:333-358.

Schoen R, Astone NM, Young K, Nathanson CA, Fields JM. Do fertility intentions affect fertility behavior? J Marriage Fam. 1999; 61:790-799.

Schultz PT. An economic model of family planning and fertility. J Polit Econ. 1969; 77:153-180. [PubMed: 11619428]

Scrimshaw SCM. Infant mortality and behavior in the regulation of family size. Popul Dev Rev. 1978; 4:383-403.

Shenk MK. Testing three evolutionary models of the demographic transition: patterns of fertility and age at marriage in urban South India. Am J Hum Biol. 2009; 21:501-511. [PubMed: 19408251]

Smuts B. Male Aggression against women: an evolutionary perspective. Hum Nat. 1992; 3:1-44.

Speidel JJ, Weiss DC, Ethelston SA, Gilbert SM. Family planning and reproductive health: the link to environmental preservation. Popul Environ. 2007; 28:247-258.

Stearns, S. The evolution of life histories. New York: Oxford University Press; 1992.

Stieglitz J, Kaplan H, Gurven M, Winking J, Vie Tayo B. Spousal violence and paternal disinvestment among Tsimane forage-horticulturists. Am J Hum Biol. 2011; 23:455-457.

Terborgh A, Rosen J, Santiso Galvez R, Terceros W, Bertrand JT, Bull SE. Family planning among indigenous populations in Latin America. Int Fam Plan Perspec. 1995; 21:143-149.

Thomson E. Couple childbearing desires, intentions, and births. Demography. 1997; 34:343-354. [PubMed: 9275244]

United Nations. Fertility behaviour in the context of development: evidence from the World Fertility Survey. New York: United Nations; 1987.

Valeggia, C.; Ellison, P. Energetics, fecundity, and human life history. In: Rodgers, JL.; Kohler, H., editors. The biodemogrpahy of human reproduction and fertility. MA: Kluwer Academic Publishers; 2003. p. 87-104.

Vining D. Social versus reproductive success: the central theoretical problem of human sociobiology. Behav Brain Sci. 1986; 9:167-260.

Voas D. Conflicting preferences: a reason fertility tends to be too high or too low. Popul Dev Rev. 2003; 29:627-646. 
Voland E. Evolutionary ecology of human reproduction. Annu Rev Anthropol. 1998; 27:347-374. [PubMed: 12295433]

Von Rueden C, Gurven M, Kaplan H. The multiple dimension of male social status in an Amazonian society. Evol Hum Behav. 2008; 29:402-415. [PubMed: 19884954]

Westoff CF, Ryder NB. The predictive validity of reproductive intentions. Demography. 1977; 14:431-453. [PubMed: 913730]

Westoff CF. The potential demand for family planning: a new measure of unmet need and estimates for five Latin American countries. Int Fam Plan Perspec. 1988; 14:45-53.

Westoff, CF.; Moreno, L. Reproductive intentions and fertility in Latin America. In: Guzmán, JM.; Singh, S.; Rodríguez, G.; Pantalides, EA., editors. The fertility transition in Latin America. Oxford: Clarendon Press; 1996. p. 242-251.

Williams, JN. Human population and the hotspots revisited: a 2010 assessment. In: Zachos, FE.; Habel, JC., editors. Biodiversity hotspots: distribution and protection of conservation priority areas. Berlin Heidelberg: Springer; 2011. p. 61-81.

Wilson C, Airey P. How can a homeostatic perspective enhance demographic transition theory? Popul Stud. 1999; 53:117-128.

Wood JW. Maternal nutrition and reproduction: why demographers and physiologists disagree about a fundamental relationship. Ann NY Acad Sci. 1994; 709:101-116. [PubMed: 8154695] 


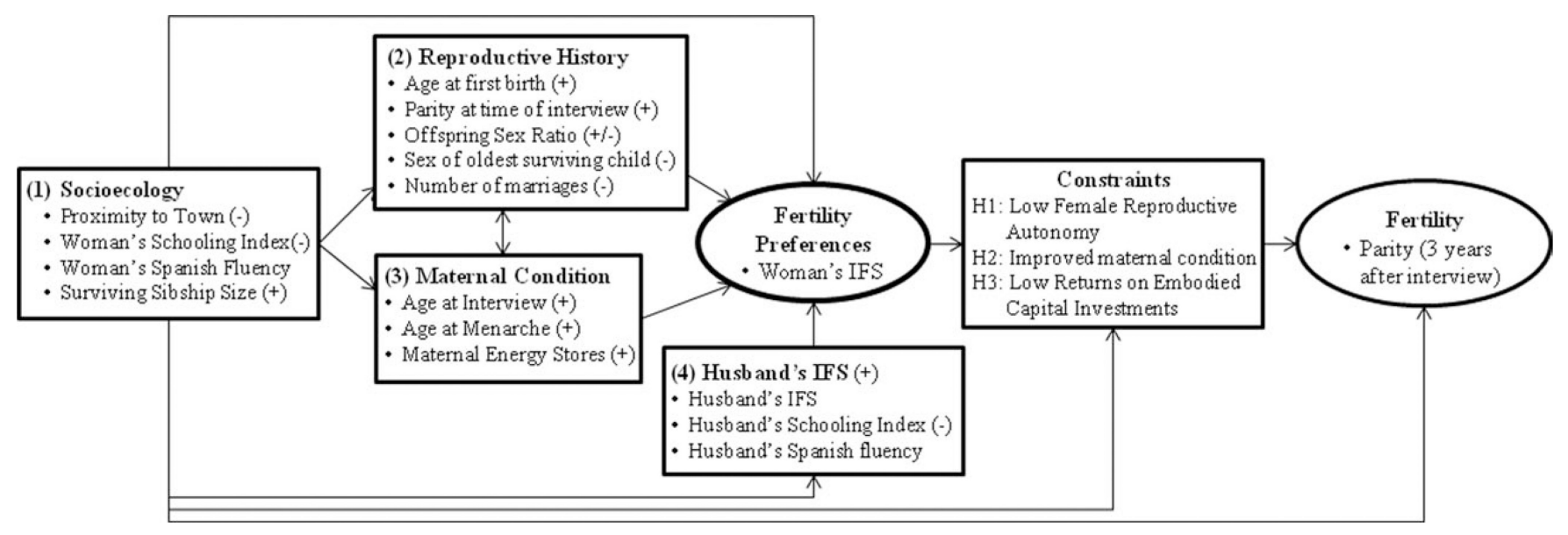

Fig. 1.

Conceptual model of factors influencing women's IFS. The + and - symbols indicate the predicted direction of effect $(+=$ positive, $-=$ negative). 
The Discrepancy Between Women's IFS and Fertility by their Age Cohort

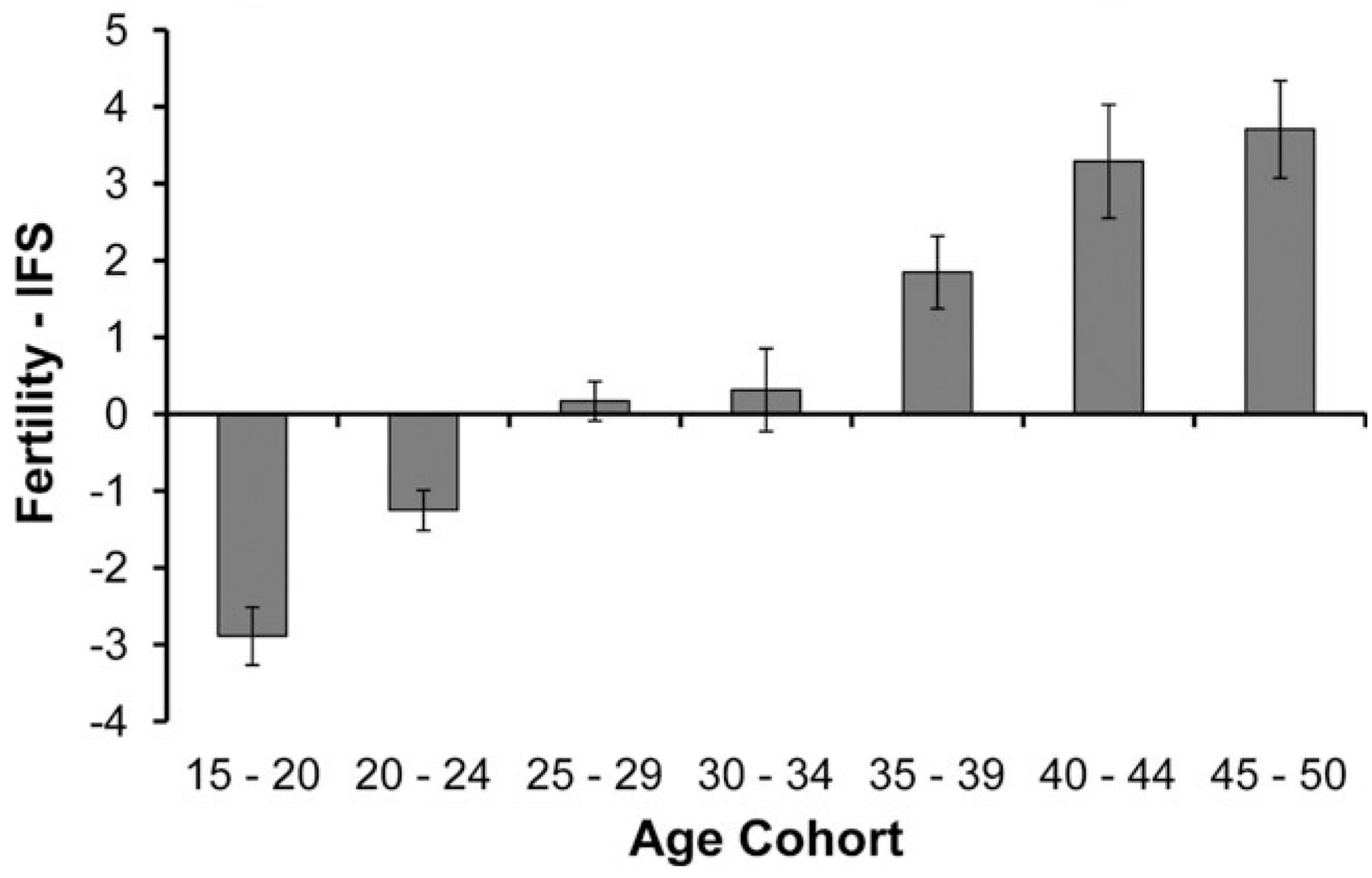

Fig. 2.

The discrepancy between women's IFS and fertility by women's age with the standard error of the mean shown. 


\section{Women's and their Husbands' IFS by Region}

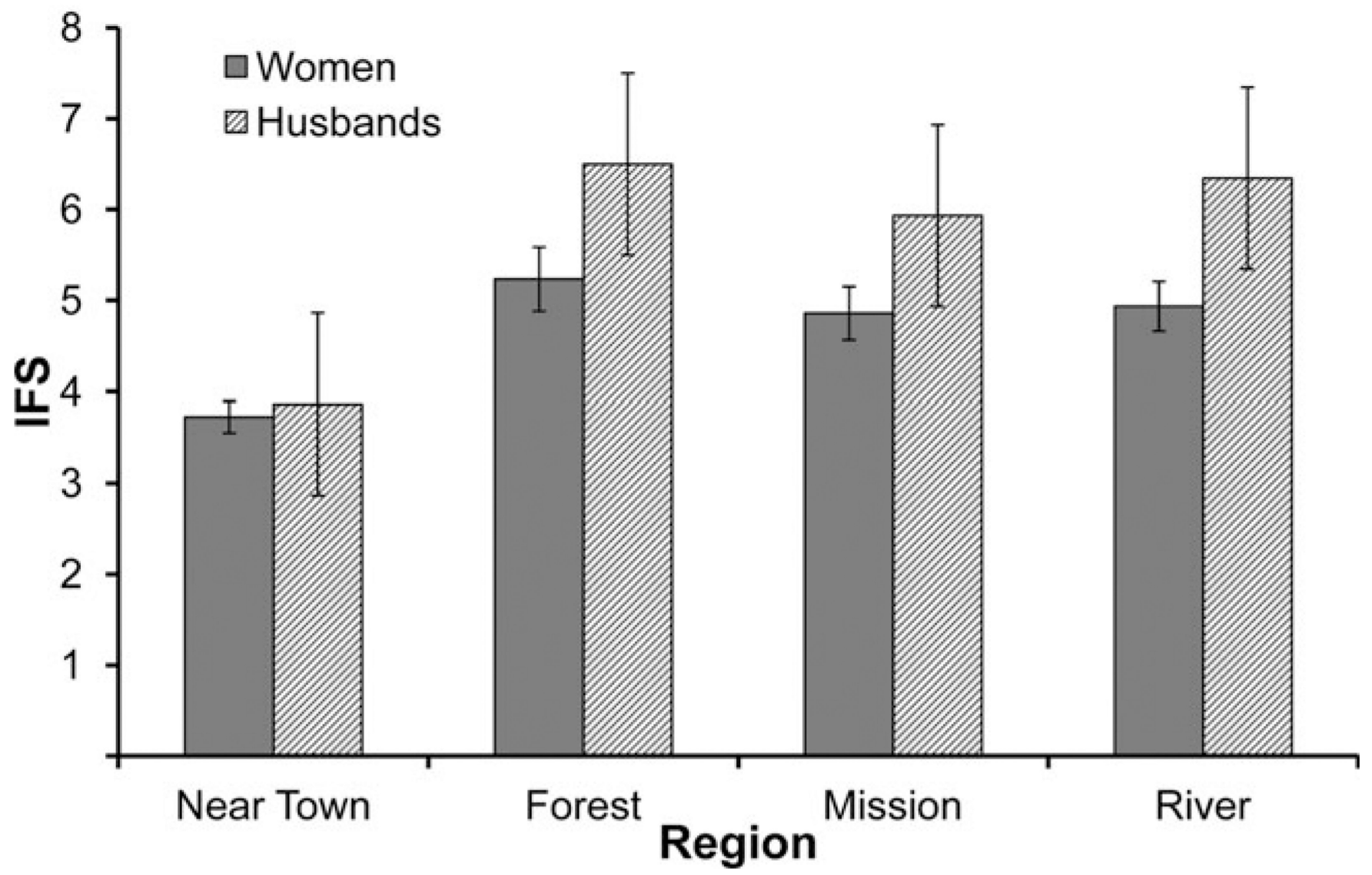

Fig. 3.

Mean IFS for women and their husbands' by region with the standard deviation of the mean shown. 


\section{Spousal Discrepancy in IFS against Women's Excess Fertility}

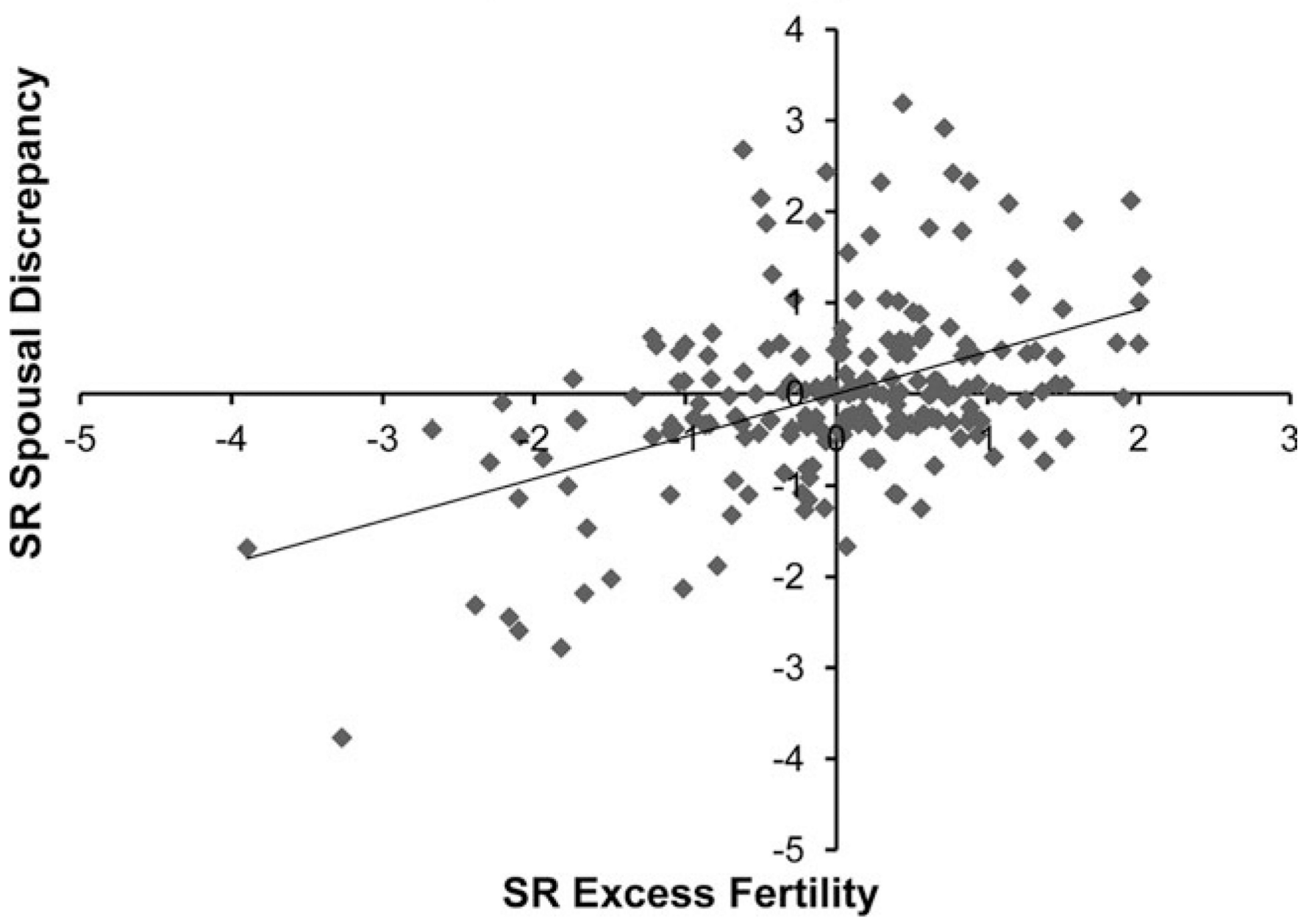

Fig. 4.

Standard residuals of women's excess fertility (women's parity at time of interviewwomen's IFS) controlling for age and distance to town against the standardized residual of spousal disparity (husband's IFS—wife's IFS) controlling for age and distance to town. 


\section{Where Tsimane Women Would Prefer to Live}

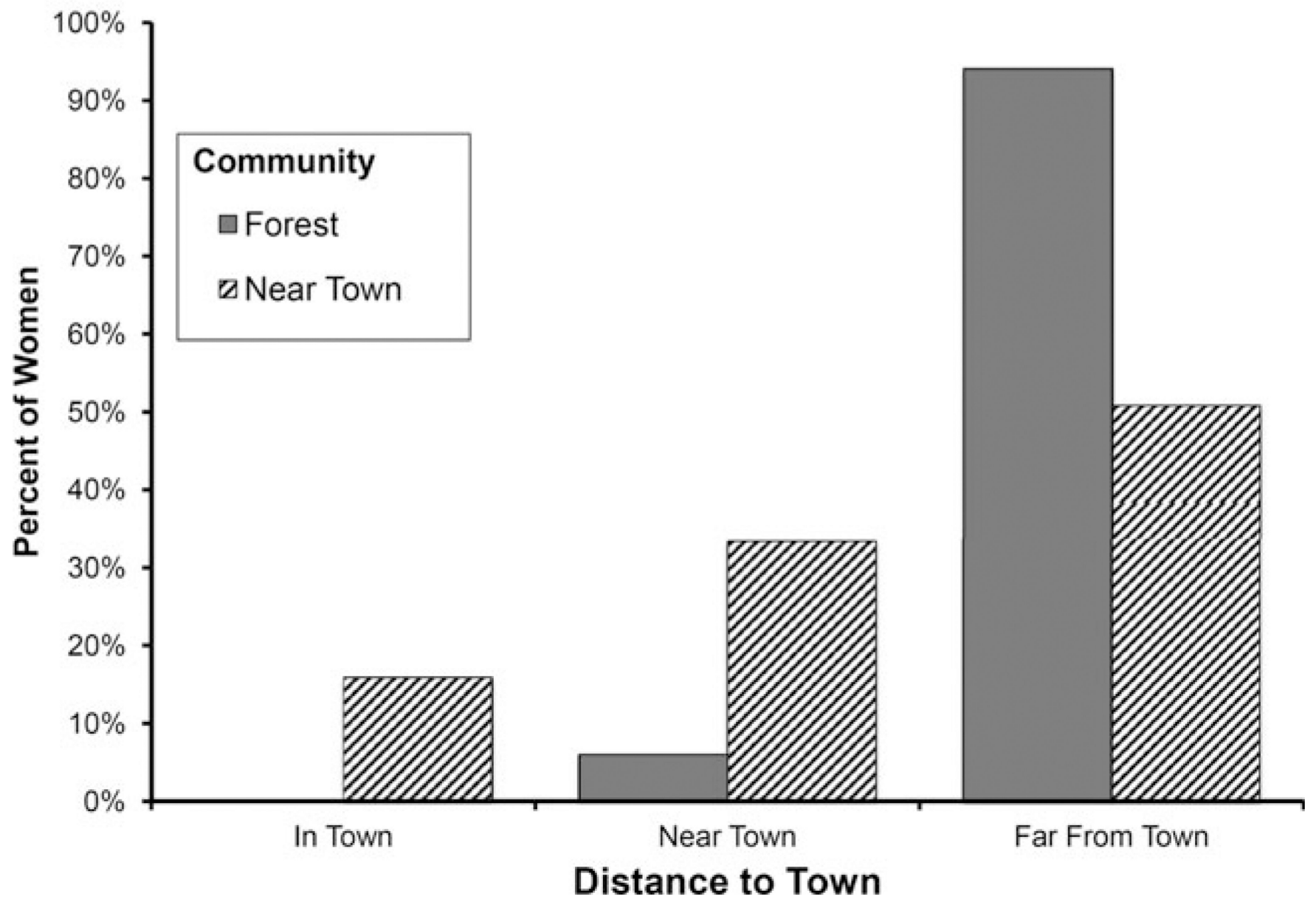

Fig. 5.

Comparing where Tsimane women from a forest village $(N=17)$ and a near town village $(N$ $=57$ ) would prefer to live. 


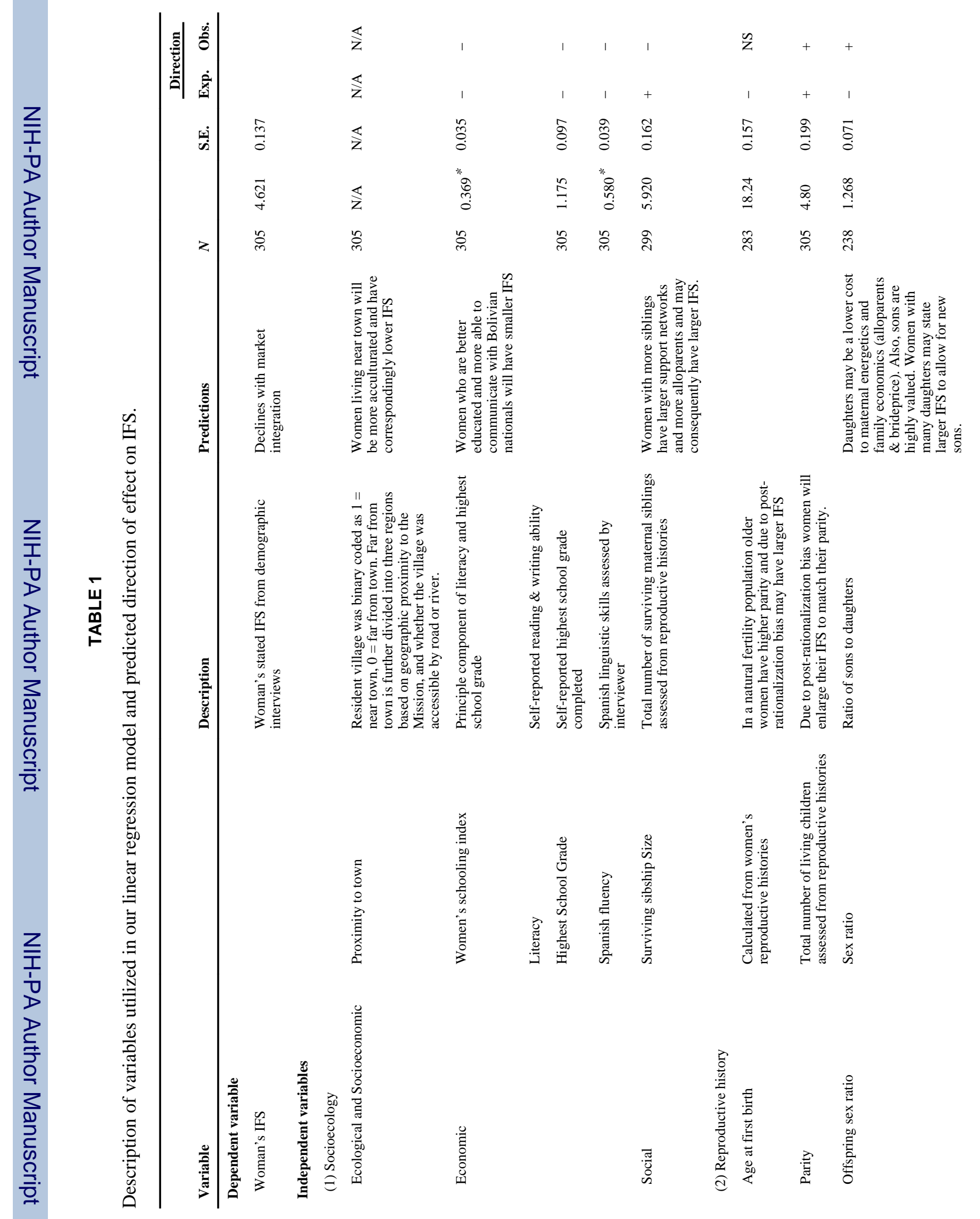




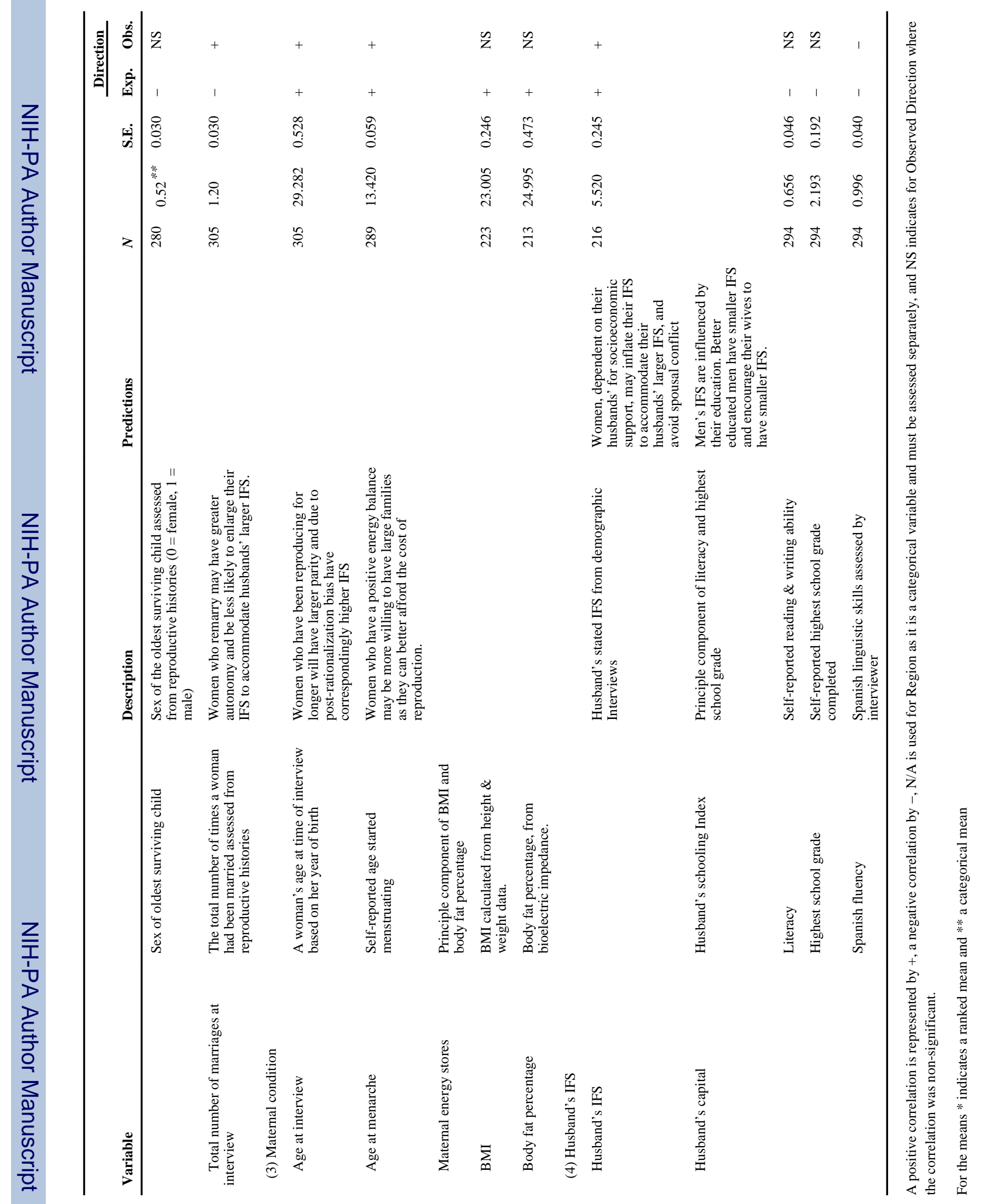




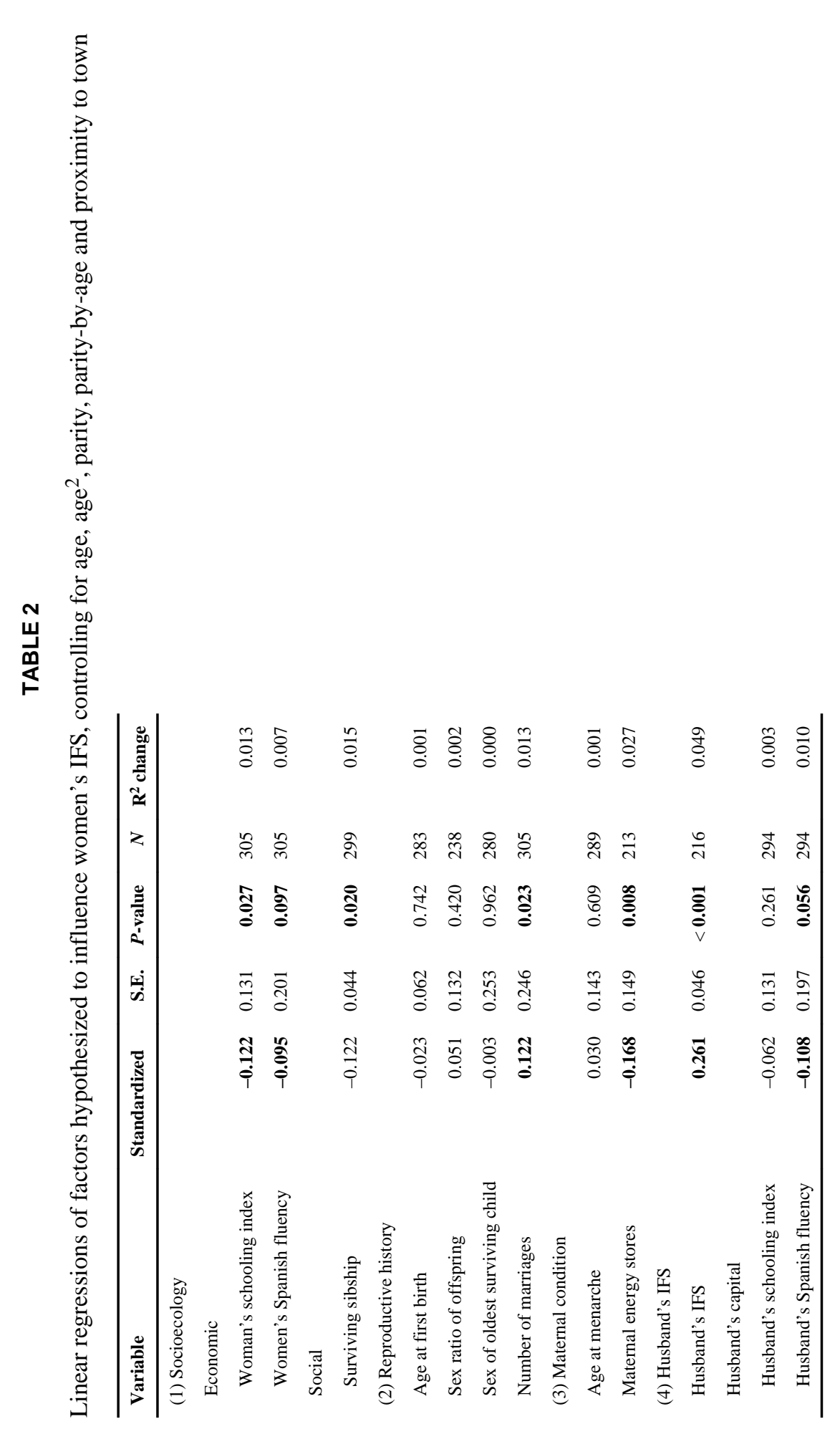


$\stackrel{0}{\Xi}$

总曾

造造

壱

ะ

当 急

芯

흔

至告

要

ญ छ

$\because$

记

ิㅡำ

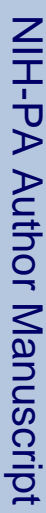

悹

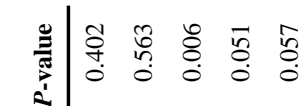

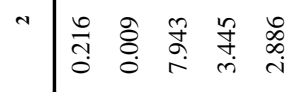

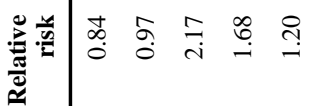

흘

릉

+
$\uplus$

茜

23

気 ฮี

ते

\&

苛

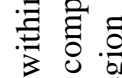

웜

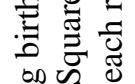

,

:

पै है चี

药

\begin{tabular}{|c|c|c|c|c|}
\hline 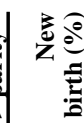 & ले & $\begin{array}{l}\hat{\sigma} \\
\dot{\sigma}\end{array}$ & 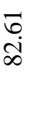 & $\begin{array}{l}n \\
\dot{b} \\
\dot{b} \\
n\end{array}$ \\
\hline$\dot{z}$ & $\stackrel{\circ}{\underline{\prime}}$ & 은 & 2 & ते \\
\hline$\dot{\mathrm{z}}$ & \& & ¿े & 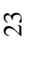 & n. \\
\hline & $\begin{array}{l}\infty \\
\varnothing \\
\beta \\
\beta\end{array}$ & 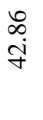 & $\stackrel{\substack{\infty \\
\infty}}{\infty}$ & $\underset{\text { di }}{\stackrel{i}{i}}$ \\
\hline & in & $\simeq$ & $\infty$ & $\sigma$ \\
\hline$\dot{\mathrm{z}}$ & F & $\underset{\sim}{\infty}$ & $\bar{\sim}$ & i \\
\hline 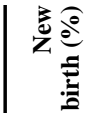 & 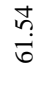 & $\stackrel{\overrightarrow{\vec{j}}}{\vec{g}}$ & గn & $\begin{array}{l}\vec{n} \\
\tilde{\sigma}\end{array}$ \\
\hline 苞 & in & $\widehat{\lambda}$ & q & q \\
\hline$\dot{\dot{z}} \overline{\tilde{g}}$ & $\bar{\sigma}$ & t & t & $\infty$ \\
\hline 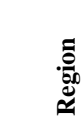 & $\bar{\sigma}$ & 苟 & $\frac{5}{5}$ & \\
\hline
\end{tabular}

